\title{
Inovasi media pembelajaran game edukasi berbasis Visual Basic pada mata pelajaran pendidikan kewarganegaraan
}

\author{
Emy Yunita Rahma Pratiwi *, Muhammad Bambang Edi Siswanto \\ Universitas Hasyim Asy'ari. \\ J1. Irian Jaya No. 55, Cukir, Diwek, Jombang, Jawa Timur 61471, Indonesia. \\ emyyunita88@gmail.com \\ * Corresponding Author
}

\section{ARTICLE INFO \\ Article History \\ Received: \\ 3 August 2020; \\ Revised: \\ 11 September 2020; \\ Accepted: \\ 21 October 2020}

\section{Keywords}

Game edukasi;

Media pembelajaran;

Pendidikan

kewarganegaraan;

Visual Basic;

Civic education,

Educational Game;

Learning media

\begin{abstract}
Pada umumnya peserta didik merasa enggan untuk mempelajari pendidikan kewarganegaraan. Beberapa problematikanya adalah pembelajaran pendidikan kewarganegaraan yang cenderung tidak menarik, membosankan, kekeliruan mahasiswa dalam memaknai dan memahami nilai-nilai yang terkandung dalam pendidikan kewarganegaraan, terbatasnya waktu yang digunakan untuk membuat media pembelajaran, kurangnya keterampilan yang dimiliki dalam membuat media pembelajaran berbasis TIK, dan tidak tersedianya biaya. Oleh karena itu, perlu adanya upaya untuk meningkatkan pembelajaran pendidikan kewarganegaraan. Tujuan penelitian ini adalah untuk menghasilkan suatu media yang siap untuk diisi konten dan skenario penggunaanya, sehingga menjadi media yang menarik dan dapat meningkatkan motivasi belajar mahasiswa. Metode penelitian ini berbentuk kuantitatif dan kualitatif. Data kuantitatif data yang diperoleh dengan menggunakan kuesioner atau angket, sedangkan data kualitatif berupa: 1.) Data awal mengenai hasil observasi dan wawancara dengan dosen mata kuliah pendidikan kewarganegaraan terhadap pelaksanaan pembelajaran di kelas; dan 2.) Data komentar dan saran dari para validator. Target capaian dalam penelitian ini adalah untuk menghasilkan produk berupa media pembelajaran game edukasi dengan Microsoft Power Point berbasis Visual Basic pada mata pelajaran pendidikan kewarganegaraan yang digunakan untuk meningkatkan proses pembelajaran maupun kompetensi peserta didik.
\end{abstract}

In general, students feel reluctant to study civic education. Some of the problems are civic education learning which tends to be unattractive, boring, student mistakes in interpreting and understanding the values contained in civic education, limited time spent making learning media, lack of skills in making ICTbased learning media, unavailability cost. Therefore, there is a need for efforts to improve civic education learning. The purpose of this research is to produce a media that is ready to be filled with content and scenarios for its use so that it becomes an attractive medium and can increase student motivation to learn. This research method is quantitative and qualitative. Quantitative data are data obtained using a questionnaire/questionnaire. While the qualitative data is in the form of 1) preliminary data regarding the results of observations and interviews with lecturers of civic education courses on the implementation of learning in class, 2) data on comments and suggestions from the validators. The target of the achievement is to produce a product in the form of learning media for educational games with Visual Basic-Based Microsoft PowerPoints in citizenship education subjects that are used to improve the learning process and the competence of students.

This is an open access article under the CC-BY-SA license. 


\section{PENDAHULUAN}

Pendidikan kewarganegaraan memegang peranan penting dalam pendidikan dalam perkembangan ilmu pengetahuan dan teknologi (IPTEK), serta berperan penting dalam proses perkembangan teknologi pada abad ke-21 sekarang ini (Hamalik, 2010). Pada umumnya peserta didik merasa enggan untuk mempelajari materi pendidikan kewarganegaraan karena beberapa problematika, diantaranya bahwa pembelajaran pendidikan kewarganegaraan cenderung tidak menarik, membosankan, serta kekeliruan peserta didik dalam memaknai dan memahami nilai-nilai yang terkandung dalam pendidikan kewarganegaraan. Di saming itu juga keterbatasan waktu yang digunakan untuk membuat media pembelajaran, kurangnya keterampilan yang dimiliki dalam membuat media pembelajaran berbasis TIK, dan tidak tersedianya biaya menjadi salah satu faktor dalam kurang menariknya proses penyaluran informasi pendidikan kewarganegaraan kepada peserta didik. Umumnya pada saat proses kegiatan pembelajaran pendidikan kewarganegaraan, berdasarkan hasil observasi yang dilakukan oleh peneliti, pendidik cenderung menggunakan media dari Microsoft PowerPoint yang seadanya dan metode ceramah daripada menggunakan media pembelajaran berbasiskan TIK. Hal ini akan berdampak pada motivasi dan minat peserta didik dalam belajar, karena kurangnya variasi dalam pembelajaran. Oleh karena itu, perlu adanya upaya untuk meningkatkan pembelajaran pendidikan kewarganegaraan yang menarik dan menyenangkan.

Menurut Suartama (2010) salah satu faktor yang mempengaruhi kualitas pembelajaran adalah penerapan teknologi serta pemanfaatan perkembangan teknologi dalam proses pembelajaran atau proses penyampaian informasi kepada peserta didik. Multimedia menjadi salah satu pemanfaatan perkembangan teknologi yang paling diminati dalam pembelajaran saat ini. Multimedia merupakan media yang sudah lengkap dan merupakan gabungan dari teks, grafik, audio, animasi, dan komponen-komponen media lainnya. Sudjana (2012) dalam penelitiannya mengemukakan bahwa manfaat media pembelajaran dalam proses belajar siswa, yaitu: 1.) Media pembelajaran dapat membuat lingkungan pembelajaran menjadi lebih menarik dan menumbuhkan motivasi belajar; 2.) Memberikan kemudahan pemahaman keada peserta didik; dan 3.) Peserta didik tidak hanya mendengar uraian guru saja, tetapi juga aktivitas lain seperti mengamati, melakukan, mendemonstrasikan, dan lain sebagainya, sehingga lebih banyak variasi kegiatan pembelajaran.

Hamalik (2013) mengemukakan bahwa manfaat media pembelajaran dalam proses belajar yaitu: 1.) Mengurangi verbalisme dengan meletakkan dasar-dasar yang konkret untuk berfikir; 2.) Meningkatkan perhatian peserta didik melalui model pembelajaran yang menarik; 3.) Meletakkan dasar-dasar yang penting untuk perkembangan belajar; 4.) Menumbuhkan sifat mandiri; 5.) Menumbuhkan pemikiran yang teratur dan berkelanjutan; 6.) Membantu perkembangan kemampuan berbahasa dengan menambuhkan pengertian; 7.) Memberikan pengalaman-pengalaman yang tidak mudah diperoleh dengan cara lain; dan 8.) Membantu berkembangnya efisiensi yang lebih mendalam serta keragaman yang lebih banyak dalam belajar. Multimedia pembelajaran yang digunakan hendaknya dirancang dengan tujuan agar proses pembelajaran menjadi lebih mudah, menyenangkan, dan tidak mempersulit peserta didik dalam mempelajari, serta memahami materi yang tersedia dalam multimedia pembelajaran yang digunakan. Menurut Binanto (2010) media atau multimedia terdiri dari 3 jenis, yaitu: multimedia interaktif, hiperaktif, dan linier. Multimedia interaktif adalah multimedia yang mana peserta didik dapat mengontrol apa dan kapan elemen-elemen multimedia akan ditampilkan (Ubaedillah \& Rozak, 2013). Dalam penyampaiannya, multimedia interaktif terdiri dari 8 jenis penyampaiannya, salah satunya adalah multimedia berbasiskan game.

Game pada umumnya digunakan untuk praktik materi tanpa struktur penyampaian isi materi yang terikat (Nasikhah, Widihastrini, \& Widodo, 2016). Menurut Ismail (2009, p. 112) educational game atau permainan edukasi adalah suatu kegiatan yang menyenangkan, dapat mendidik, bermanfaat untuk meningkatkan kemampuan bahasa dan berfikir, serta meningkatkan nilai sosial peserta didik dalam bergaul di lingkungan masyarakat sekitarnya. Permainan edukatif atau educational game adalah platform permainan yang dirancang dengan tujuan yang spesifik sebagai salah satu alat atau media dalam mencapai tujuan pendidikan (Kemp \& Dayton, 1985). Developer atau pengembang harus memperhitungkan berbagai hal agar educational game yang dikembangkan dapat benar-benar mendidik, menambah pengetahuan, dan meningkatkan keterampilan user yang menggunakannya (Costikyan, 2013). Target segmentasi user juga harus disesuaikan dalam 
pengembangan educational game, baik dari segi tingkat kesulitan permainan, desain animasi visual yang ditampilkan, hingga pemilihan kombinasi warna yang sesuai dengan target pengguna multimedia (Dönmez, Tekçe, \& Kirmit, 2020)

Ismail (2009, p. 138) mengungkapkan bahwa educational game dapat berfungsi sebagai: 1.) Sebagai ilmu pengetahuan yang diberikan kepada anak melalui proses pembelajaran bermain sambil belajar (learning by games); 2.) Menumbuhkan dan merangsang pengembangan daya pikir, daya cipta, dan bahasa agar dapat menumbuhkan sikap, mental, serta akhlak yang baik; 3.) Menciptakan lingkungan bermain yang menarik, memberikan rasa aman, dan menyenangkan; dan 4.) Meningkatkan kualitas pembelajaran. Penelitian sebelumnya yang dilakukan oleh Sriwahyuni (2016) menunjukkan beberapa keunggulan dalam penggunaan educational game sebagai media pembelajaran, yaitu 1.) Dapat dijadikan sebagai alat bantu untuk menjelaskan materi di dalam kelas; 2.) Dapat dijadikan media pembelajaran secara mandiri oleh peserta didik; 3.) Dapat digunakan oleh semua kalangan; 4.) Materi yang disajikan disampaikan dengan lebih ringkas dan jelas; 5.) Media pembelajaran dapat dilengkapi dengan berbagai fitur, seperti quiz dan pemberian feedback sebagai tolak ukur atau evaluasi capaian peserta didik; dan 6.) Ukuran file yang relatif lebih kecil ketimbang media pembelajaran dengan menggunakan video pembelajaran. Menurut Novitasari (2016) dengan menggunakan multimedia Microsoft PowerPoint berbasiskan Visual Basic dapat menjadi salah satu alternatif dalam pembelajaran di kelas.

Implementasi pendidikan karakter di sekolah semestinya didasarkan pada nilai-nilai karakter dasar yang kemudian berkembang menjadi nilai-nilai yang lebih luas sesuai dengan kebutuhan, kondisi, dan lingkungan sekolah itu sendiri. Hal ini sesuai dengan penelitian yang dilakukan oleh Saputra (2012) yang menganalisia keberadaan pembelajaran pendidikan kewarganegaraan sebagai pendidikan nilai dalam membangun karakter bangsa. Penelitian yang dilakukan oleh Akbal (2016) menunjukkan bahwa salah satu indikator penentu eksistensi bangsa dan negara adalah apabila masyarakatnya memiliki nilai-nilai karakter yang baik yang sesuai dengan dasar falsafah negaranya. Nilai-nilai karakter yang dibangun melalui pendidikan kewarganegaraan secara yuridis formal menjadi salah satu mata pelajaran wajib disetiap jenjang pendidikan, mulai dari sekolah dasar sampai dengan perguruan tinggi. Penelitian yang dilakukan oleh Aji (2018) mendeskripsikan peranan pendidikan kewarganegaraan sebagai pembentukan karakter peserta didik melalui proses pendekatan berbasis nilai untuk mewujudkan good citizen.

Berdasar uraian tersebut, peneliti mencoba melakukan inovasi dengan memanfaatkan dan mengembangkan media pembelajaran dengan PowerPoint berbasiskan Visual Basic untuk permainan edukasi atau educational game sebagai wadah soal-soal pilihan ganda dan essay dan penyajian informasi dalam beberapa format, diantaranya berupa audio, video, teks, animasi. dan gambar. Tujuan dikembangkannya educational game pada penelitian ini adalah untuk menghasilkan suatu media yang siap diisi dengan konten materi dan skenario, sehingga dapat menarik dan dapat meningkatkan motivasi belajar peserta didik. Dengan menggunakan educational game sebagai media pembelajaran khususnya dalam pembelajaran pendidikan kewarganegaraan diharapkan pendidik dapat semakin profesional dalam merancang suatu media pembelajaran. Pendidik hanya membutuhkan waktu yang relatif singkat untuk membuat media yang menarik dan interaktif, sehingga peserta didik lebih termotivasi dalam mengikuti proses kegiatan belajar mengajar. Hal ini merupakan sesuatu yang urgensi karena jika hal tersebut tidak dilakukan, maka hasil ujian dan proses penyampaian informasi kepada peserta didik tidak akan optimal.

\section{METODE}

Metode yang digunakan dalam penelitian ini menggunakan pendekatan penelitian pengembangan atau research and development $(R \& D)$. Menurut Sugiyono (2010), metode penelitian dan pengembangan $(R \& D)$ adalah metode penelitian yang digunakan untuk menghasilkan produk tertentu dan untuk melakukan menguji keefektifan produk yang dikembangkan. Pendekatan penelitian pengembangan dalam produk multimedia pembelajaran educational game dalam penelitian ini memiliki tujuan untuk mengetahui tingkat kelayakan serta bagaimana hasil implementasi media pembelajaran pada saat diuji cobakan kepada responden. Berdasarkan metode penelitian $R \& D$, sistematika penelitian yang digunakan dalam penelitian ini adalah: analisis 
kebutuhan peserta didik, desain, implementasi, validasi desain media, revisi desain media, uji coba produk, revisi produk, dan produk akhir. Alur sistematika penelitian dengan menggunakan metode $R \& D$ menurut Sugiyono (2010) dapat dilihat pada Gambar 1.

Jenis penelitian yang digunakan dalam penelitian ini adalah $R \& D$, yaitu metode penelitian yang digunakan untuk mengembangkan atau menyempurnakan produk tertentu dan menguji keefektifan produk tersebut. Penelitian dilakukan di Program Studi PGSD Universitas Hasyim Asy'ari Jombang yang beralamat di Jl. Irian Jaya No. 55, Cukir, Diwek, Kabupaten Jombang, Jawa Timur. Responden dalam penelitian ini sebanyak 25 orang mahasiswa Program Studi PGSD Universitas Hasyim Asy'ari Jombang yang menempuh mata kuliah pendidikan kewarganegaraan. Teknik pengumpulan data dilakukan melalui wawancara, kuisioner (angket), observasi, dan dokumentasi. Penggunaan metode penelitian ini berbentuk kuantitatif dan kualitatif. Data kuantitatif adalah data yang diperoleh dengan menggunakan kuesioner atau angket, yang terdiri dari: 1.) Angket validasi instrumen, validasi materi, validasi media, dan uji coba media pembelajaran; 2.) Angket validasi ahli materi, angket validasi ahli media, dan angket uji coba produk media pembelajaran, sedangkan data kualitatif berupa: 1.) Data awal mengenai hasil observasi dan wawancara dengan dosen mata kuliah pendidikan kewarganegaraan terhadap pelaksanaan pembelajaran di kelas; dan 2.) Data komentar dan saran dari para validator.

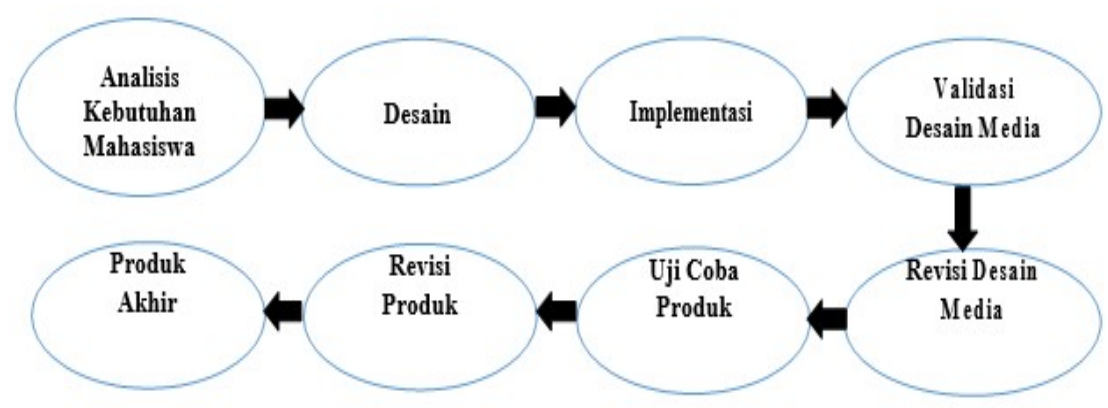

Gambar 1. Metode Research \& Develoment (Sugiyono, 2010)

\section{HASIL DAN PEMBAHASAN}

Hasil penelitian diawali dengan validasi penilaian yang dilakukan oleh para ahli, yaitu ahli materi dan ahli media pembelajaran. Aspek-aspek penilaian materi yang dinilai adalah: 1.) Identitas RPP; 2.) Perumusan indikator; 3.) Perumusan tujuan pembelajaran; 4.) Pemilihan materi ajar; 5.) Pemilihan sumber belajar; 6.) Pemilihan media belajar; 7.) Metode pembelajaran; 8.) Skenario pembelajaran; 9.) Penilaian; 10.) Lembar kerja siswa (LKS); dan 11.) Bahasa. Rekapitulasi data penilaian hasil validasi perangkat pembelajaran dapat dilihat pada Tabel 1.

Tabel 1. Hasil Validasi Penilaian oleh Ahli Materi

\begin{tabular}{lcc}
\hline \multicolumn{1}{c}{ Aspek yang dinilai } & \multicolumn{2}{c}{ Hasil Perolehan Skor } \\
& Validator I & Validator II \\
\hline Identitas RPP & 8 & 7 \\
Perumusan Indikator & 11 & 11 \\
Tujuan pembelajaran & 8 & 8 \\
Pemilihan materi ajar & 11 & 11 \\
Pemilihan sumber belajar & 16 & 16 \\
Pemilihan media belajar & 11 & 12 \\
Metode pembelajaran & 7 & 5 \\
Skenario pembelajaran & 19 & 20 \\
Penilaian & 21 & 19 \\
Lembar kerja siswa (LKS) & 16 & 14 \\
Bahasa & 4 & 3 \\
Total skor keseluruhan & 132 & 126 \\
\hline
\end{tabular}


Tabel 2. Hasil Validasi Penilaian Ahli Media

\begin{tabular}{lcc}
\hline \multicolumn{1}{c}{ Aspek yang dinilai } & \multicolumn{2}{c}{ Hasil perolehan skor } \\
& Validator Ibu A & Validator Ibu B \\
\hline Aspek audio visual & 69 & 72 \\
Aspek isi & 36 & 35 \\
Aspek lainnya & 22 & 24 \\
Total keseluruhan & 127 & 131 \\
Rerata & 3,73 & 3,85 \\
Kriteria & Sangat baik & Sangat baik \\
\hline
\end{tabular}

Tabel 3. Komentar Para Ahli Media Pembelajaran Berbasis TIK



Berdasarkan pada Tabel 1, hasil validasi ahli materi terhadap materi pembelajaran yang disajikan dalam media pembelajaran educational game yang dikembangkan mendapatkan rata-rata penilaian dari validator 1 sebesar 3,8 dan validator 2 sebesar 3,7 dengan kategori sangat baik, nilai rata-rata dari kedua validator adalah sebesar 3,73 dengan kategori sangat baik. Materi yang disajikan dalam media pembelajaran educational game yang dikembangkan mengacu pada kurikulum 2006 (KTSP) dan dinyatakan layak digunakan atau diujicobakan dengan revisi sesuai saran. Selanjutnya, aspek yang dinilai dari desain media pembelajaran educational game yang dikembangkan, yaitu: 
aspek audio visual, aspek isi, dan aspek lainnya. Data hasil validasi media pembelajaran oleh ahli media dapat dilihat pada Tabel 2.

Berdasarkan pada Tabel 2 hasil validasi penilaian ahli media terhadap media pembelajaran yang dikembangkan menunjukan rerata skor keseluruhan hasil validasi dari ahli media sebesar 3,79 dan masuk dalam kategori sangat baik, sehingga disimpulkan bahwa berdasarkan hasil validasi ahli media, media pembelajaran educational game layak untuk diujicoba dengan revisi. Pembuatan media pembelajaran harus disesuaikan dengan fungsi media pembelajaran sebagaimana diungkapkan oleh Munadi (2010, p. 36) bahwa media pembelajaran yang dikembangkan harus difokuskan ada fungsi: sebagai sumber belajar, fungsi semantik, fungsi manipulatif, fungsi psikologi, dan fungsi sosio kultural. Revisi produk digunakan sebagai perbaikan dalam pengembangan produk agar media pembelajaran yang dikembangkan layak untuk digunakan. Revisi produk dilakukan sesuai dengan saran dari para ahli, yaitu ahli media dan ahli materi. Komentar atau saran ahli media terhadap revisi media pembelajaran pada aspek audio visual dapat dilihat pada Tabel 3.

Soal yang disajikan pada media pembelajaran educational game sudah melalui tahap penghitungan uji validitas dan reliabilitas dengan menggunakan software SPSS. Tujuan dari uji validitas dan reliabilitas tersebut yaitu sebagai acuan revisi soal evaluasi. Soal-soal yang disajikan dinyatakan valid jika sig $\leq 0,05$. Hasil validitas soal pilihan ganda dengan menggunakan software SPSS dapat dilihat pada Tabel 4. Hasil uji validitas dengan menggunakan software SPSS terdahap tes pilihan ganda berdasarkan pada Tabel 5 memperoleh hasil bahwa dari 10 soal yang disajikan kesemuanya dinyatakan valid. Hasil reliabilitas yang dilakukan memperoleh koefisien sebesar 0,562. Uji reliabilitas dikatakan reliable karena Cronbach's Alpha kurang dari 0,6. Setelah uji validitas dan reliabilitas selanjutnya dilakukan uji coba pemakaian.

Tabel 4. Hasil Validitas Soal Pilihan Ganda

\begin{tabular}{ccc}
\hline No. & Sig. 2 tailed & Keputusan \\
\hline 1. & 0.007 & Valid \\
2. & 0.006 & Valid \\
3. & 0.005 & Valid \\
4. & 0.017 & Valid \\
5. & 0.027 & Valid \\
6. & 0.045 & Valid \\
7. & 0.003 & Valid \\
8. & 0.008 & Valid \\
9. & 0.009 & Valid \\
10. & 0.028 & Valid \\
\hline
\end{tabular}

Setelah melakukan proses kegiatan pembelajaran dengan menggunakan media educational game yang dikembangkan, selanjutnya peserta didik diminta untuk mengisi angket kuesioner yang berisi respon terhadap proses pembelajaran yang telah dilakukan. Jumlah responden yang mengisi angket sebanyak 25 orang. Tujuan dilakukan pengisian angket adalah untuk melihat respon terhadap penggunaan media pembelajaran educational game yang diimplementasikan pada kegiatan pembelajaran. Aspek yang dinilai meliputi: aspek minat peserta didik, aspek tampilan, dan aspek bahasa. Hasil rekapitulasi penilaian yang dilakukan oleh responden terhadap media pembelajaran educational game dapat dilihat pada Tabel 5. Berdasarkan data pada Tabel 5, dapat disimpulkan bahwa hasil rata-rata skor mendapatkan nilai sebesar 88,4 dengan kategori sangat baik.

Media pembelajaran interaktif berbasiskan PowerPoint dengan materi moral, nilai, dan norma pada mata kuliah pendidikan kewarganegaraan dikembangkan berdasarkan langkah-langkah desain pembelajaran menurut Borg dan Gall. Langkah-langkah menurut Borg dan Gall tersebut dimulai dengan mengidentifikasi potensi dan masalah, melakukan pengumpulan data, mendesain produk, melakukan validasi desain, revisi desain, uji coba produk, revisi produk, uji coba pemakaian, dan revisi akhir (Basuki, 2014). Dalam pengembangan media pembelajaran, peneliti memperhatikan kriteria media pembelajaran yang baik berdasarkan saran dan masukan para ahli, agar media yang dibuat sesuai dengan tujuan pembelajaran (Subiyanto, 2017). Pengembangan media pembelajaran 
educational games dalam penelitian ini telah melalui tahap validasi oleh ahli media dan ahli materi. Pedoman dalam melakukan validasi didasarkan pada tiga aspek yaitu: aspek audio visual, aspek isi, dan aspek lainnya. Hasil rekapitulasi penilaian yang dilakukan oleh ahli media dan materi dapat dilihat pada Tabel 6 .

Tabel 5. Penilaian Responden Hasil Uji Coba Produk

\begin{tabular}{|c|c|c|c|}
\hline No & Jumlah Skor & Nilai & Klasifikasi \\
\hline 1 & 90 & 90 & Baik Sekali \\
\hline 2 & 80 & 80 & Baik Sekali \\
\hline 3 & 70 & 70 & Baik Sekali \\
\hline 4 & 80 & 80 & Baik Sekali \\
\hline 5 & 90 & 90 & Baik Sekali \\
\hline 6 & 100 & 100 & Baik Sekali \\
\hline 7 & 100 & 100 & Baik Sekali \\
\hline 8 & 80 & 80 & Baik Sekali \\
\hline 9 & 70 & 70 & Baik Sekali \\
\hline 10 & 80 & 80 & Baik Sekali \\
\hline 11 & 90 & 90 & Baik Sekali \\
\hline 12 & 100 & 100 & Baik Sekali \\
\hline 13 & 80 & 80 & Baik Sekali \\
\hline 14 & 90 & 90 & Baik Sekali \\
\hline 15 & 90 & 90 & Baik Sekali \\
\hline 16 & 80 & 80 & Baik Sekali \\
\hline 17 & 80 & 80 & Baik Sekali \\
\hline 18 & 90 & 90 & Baik Sekali \\
\hline 19 & 100 & 100 & Baik Sekali \\
\hline 20 & 80 & 80 & Baik Sekali \\
\hline 21 & 90 & 90 & Baik Sekali \\
\hline 22 & 100 & 100 & Baik Sekali \\
\hline 23 & 100 & 100 & Baik Sekali \\
\hline 24 & 100 & 100 & Baik Sekali \\
\hline 25 & 100 & 100 & Baik Sekali \\
\hline Jumlah & & 2210 & Baik Sekali \\
\hline Rata-rata & & 88,4 & \\
\hline
\end{tabular}

Tabel 6. Rekapitulasi Hasil Validasi Penilaian Ahli Media dan Materi

\begin{tabular}{cccc}
\hline \multirow{2}{*}{ No } & \multirow{2}{*}{ Validator } & \multicolumn{2}{c}{ Hasil validasi media pembelajaran } \\
& & Rerata Skor & Kategori \\
\hline 1 & Ahli Media A & 3,83 & Sangat baik \\
2 & Ahli Media B & 3,95 & Sangat baik \\
3 & Ahli Materi A & 3,84 & Sangat baik \\
4 & Ahli Materi B & 3,75 & \multicolumn{2}{c}{ Sangat baik } \\
Jumlah & & \multicolumn{2}{c}{15,37} \\
Rerata & & \multicolumn{2}{c}{ Sangat baik } \\
Kategori & & \multicolumn{3}{c}{ Sang } \\
\hline
\end{tabular}

Berdasarkan Tabel 6 rekapitulasi validasi dari ahli media dan materi memperoleh skor ratarata keseluruhan sebesar 3,84. Daat disimulkan bahwa media pembelajaran educational game masuk dalam kategori sangat baik. Spesifikasi produk yang dikembangkan dalam penelitian ini antara lain: 1.) Media pembelajaran berisi pembukaan, isi, dan penutup; 2.) Media pembelajaran dibuat dengan tampilan yang menarik; 3.) Media pembelajaran dibuat dengan simbol dan tombol; 4.) Media pembelajaran dibuat dengan bahasa komunikatif; 5.) Media pembelajaran dibuat dengan perkembangan peserta didik yaitu kognitif, psikomotorik, dan afektif; dan 6.) Media pembelajaran 
dibuat dengan prinsip para ahli. Hasil pengembangan media pembelajaran meliputi alat atau media yang secara fisik dapat digunakan untuk menyampaikan isi materi pembelajaran, yang terdiri antara lain dari buku, tape-recorder, video camera, video recorder, film, slide (gambar bingkai), foto, gambar, grafik, televisi dan pesonal computer (Arsyad, 2014, p. 4). Pengembangan media pembelajaran bertujuan untuk menarik minat peserta didik (Yunita, 2014). Selain mengembangkan dan menampilkan media pembelajaran yang menarik, dalam penelitian ini juga terdapat fitur game yang dapat menjadi sarana hiburan bagi peserta didik untuk menambahkan semangat dan motivasi peserta didik dalam belajar (Samuel, 2010). Game edukatif selayaknya dibuat dengan tujuan spesifik sebagai alat pendidikan, baik untuk belajar mengenal warna untuk balita, mengenal huruf dan angka, matematika, sampai dengan belajar bahasa asing (Schrader, Lawless, \& Deniz, 2010)

Hasil penelitian media pembelajaran educational game yang dikembangkan sesuai dengan penelitian sebelumnya yang dilakukan oleh Novitasari (2016) yang memberikan sudut pandang bahwa dengan menggunakan multimedia berbasis PowerPoint dengan Visual Basic dapat menjadi salah satu alternatif yang menarik untuk pembelajaran di kelas sekaligus sebagai karya inovatif pengajar. Tujuan dalam dikembangkannya multimedia ini yaitu untuk meningkatkan motivasi belajar peserta didik khusunya dalam materi pendidikan kewarganegaraan. Penelitian yang dilakukan juga sesuai dengan penelitian sebelumnya yang dilakukan oleh Saputra (2012) yang menganalisis bahwa keberadaan pembelajaran pendidikan kewarganegaraan adalah sebagai pendidikan nilai dalam membangun karakter bangsa. Implementasi pendidikan karakter di sekolah harus didasarkan pada nilai-nilai karakter dasar, yang kemudian berkembang menjadi nilai-nilai yang lebih luas sesuai dengan kebutuhan dan kondisi (Angraini, 2017)

Aji (2018) mendeskripsikan peranan pendidikan kewarganegaraan dalam upaya pembentukan karakter kewarganegaraan peserta didik melalui proses pendekatan berbasis nilai pada pembelajaran mata kuliah pendidikan kewarganegaraan yaitu mewujudkan good citizen. Pendidikan kewarganegaraan di perguruan tinggi adalah bagaimana mendidik para mahasiswa sebagai calon intelektual bangsa untuk dapat menjadi warga negara yang baik yang dapat memahami tentang substansi nilai-nilai falsafah negaranya, memiliki kepribadian yang sesuai dengan etika bangsa, berpandangan luas, dan mampu bersikap demokratis yang berkeadaban (Dayan \& Umar, 2017). Hal tersebut sesuai dengan pendapat Ubaedillah dan Rozak (2013) yang menyatakan bahwa pendidikan kewarganegaraan adalah pendidikan demokrasi yang bertujuan untuk mempersiapkan warga masyarakat untuk daat berfikir kritis dan bertindak demokratis melalui aktivitas menanamkan kesadaran kepada generasi baru tentang kesadaran bahwa demokrasi adalah bentuk kehidupan yang paling menjamin hak-hak warga masyarakat. Oleh karena itu, pembelajaran pendidikan kewarganegaraan didesain sedemikian rupa untuk meningkatkan kesadaran sebagai pendidikan civilization (Nasikhah, Widihastrini, \& Widodo, 2016). Materi yang disajikan dalam media pembelajaran telah sesuai dengan tujuan pendidikan kewarganegaraan yang berarti pendidikan pengetahuan, sikap, mental, nilai-nilai, dan prilaku yang menjunjung tinggi demokrasi, sehingga terwujud warga masyarakat yang demokratis dan mampu menjaga persatuan dan integritas bangsa guna mewujudkan Indonesia yang kuat, sejahtera, serta demokratis (Aryani, 2010, p. 40).

\section{SIMPULAN}

Berdasarkan hasil penelitian dan pembahasan yang telah dilakukan oleh peneliti mengenai pengembangan media pembelajaran educational game dengan menggunakan Power Point berbasis Visual Basic untuk mata pelajaran pendidikan kewarganegaraan, maka dapat disimpulkan beberapa hal sebagai berikut: 1.) Pengembangan media pembelajaran educational game dilakukan dengan prosedur penelitian pengembangan Borg dan Gall. Prosedur penelitian pengembangan berdasarkan Brog dan Gall mempunyai 10 langkah pengembangan, namun peneliti hanya sampai pada langkah 9 karena terbatasnya waktu penelitian dan hanya divalidasi oleh dua orang ahli atau pakar. Sembilan langkah tersebut, yaitu: a.) Mengidentifikasi potensi dan masalah; b.) Melakukan pengumpulan data; c.) Desain produk; d.) Validasi desain; e.) Revisi desain; f.) Melakukan uji coba produk; g.) Revisi produk; h.) Uji coba pemakaian; dan i.) Revisi produk; 2.) Media Pembelajaran education game yang dikembangkan memiliki spesialisasi produk sebagai berikut: a.) Media pembelajaran educational game yang dikembangkan berisi pembukaan, isi, dan penutup; b.) Media pembelajaran educational 
game yang dikembangkan disajikan dengan tampilan menarik; c.) Media pembelajaran educational game yang dikembangkan disajikan dengan simbol dan tombol yang memudahkan pengguna dalam melakukan navigasi atau menggunakan media pembelajaran; d.) Media pembelajaran educational game yang dikembangkan disajikan dengan bahasa yang komunikatif; e.) Materi media pembelajaran educational game yang dikembangkan sesuai dalam perkembangan aspek kognitif, psikomotorik dan afektif peserta didik; dan f.) Media pembelajaran educational game yang dikembangkan telah direvisi berdasarkan masukan dan saran dari para ahli; dan 3.) Hasil validasi oleh dua orang ahli media dan dua orang ahli materi mendapatkan nilai dengan rata-rata skor sebesar 3,84 dengan kategori sangat baik, sedangkan hasil uji coba produk yang dilakukan mendapatkan nilai dengan ratarata sebesar 88,4 dengan kategori sangat baik.

\section{DAFTAR PUSTAKA}

Aji, P. C. (2018). Peran PKn dalam membentuk karakter kewarganegaraan melalui pendekatan berbasis nilai di perguruan tinggi. Retrieved from https://ppkn.fkip.uns.ac.id/wpcontent/uploads/2018/08/Purnomo-Aji.-Universitas-Sebelas-Maret..pdf

Angraini, R. (2017). Karakteristik media yang tepat dalam pembelajaran pendidikan kewarganegaraan sebagai pendidikan nilai. Journal of Moral and Civic Education, 1(1), 1424. doi: https://doi.org/10.24036/8851412020171116

Arsyad, A. 2014. Media pembelajaran. Jakarta: Rajagrafindo Persada.

Aryani, I. K. 2010. Pendidikan kewarganegaraan berbasis nilai. Bogor: Ghalia Indonesia.

Basuki, I. (2014). Asesmen pembelajaran. Bandung: Remaja Rosdakarya Offset.

Binanto, I. (2010). Multimedia digital-dasar teori dan pengembangannya. Penerbit Andi..

Costikyan, G. (2013). Uncertainty in games. Cambridge: The MIT Press.

Dayan, B., \& Umar, S. Penggunaan Media Pembelajaran Pendidikan Kewarganegaraan untuk Meningkatkan Motivasi dan Hasil Belajar. Jurnal Pendidikan dan Pembelajaran Khatulistiwa, 4(1), 1-14. Retrieved https://jurnal.untan.ac.id/index.php/jpdpb/article/view/8776/8736

Dönmez, İ., Tekçe, M., \& Kirmit, Ş. (2020). Using digital games in technology oriented STEM education: The examination of the students' game designs. Journal of Education in Science, Environment and Health, 6(2), 77-91. doi: https://doi.org/10.21891/jeseh.669097

Hamalik, O. (2010). Proses belajar mengajar. Jakarta: Bumi Aksara.

Hamalik, O. (2013). Kurikulum dan pembelajaran edisi 1. Bumi Aksara, Jakarta.

Ismail, A. (2009). Education games: Panduan praktis permainan yang menjadikan anak anda cerdas, kreatif, dan saleh. Yogyakarta: Pro-U Media.

Kemp, J. E., \& Dayton, D. K. (1985). Planning and producing instructional media. Harper \& Row.

Nasikhah, A. N., Widihastrini, F., \& Widodo, S. T. (2016). Pengembangan Game Education Pembelajaran PKn Materi Menghargai Keputusan Bersama Kelas V SD. Jurnal Kreatif : Jurnal Kependidikan Dasar, 7(1), 81-91. doi: https://doi.org/10.15294/kreatif.v7i1.9370

Novitasari, D. (2016). Pengaruh penggunaan multimedia interaktif terhadap kemampuan pemahaman konsep matematis siswa. Fibonacci: Jurnal Pendidikan Matematika dan Matematika, 2(2), 8-18. doi: https://doi.org/10.24853/fbc.2.2.8-18

Samuel, H. (2010). Cerdas dengan game: Panduan praktis bagi orang tua dalam mendampingi anak bermain game. Jakarta: Gramedia Pustaka Utama.

Saputra, E. (2012). Eksistensi PKn sebagai pendidikan nilai dalam membangun karakter bangsa. Tingkap: Jurnal Ilmu-ilmu Sosial, Budaya, dan Ekonomi Fakultas Pendidikan Ilmu 
Pengetahuan Sosial IKIP Padang, 8(2), 145-158. Retrieved from http://ejournal.unp.ac.id/index.php/tingkap/article/view/1881

Schrader, P. G., Lawless, K. A., \& Deniz, H. (2010). Video games in education: Opportunities for learning beyond research claims and advertising hype. In Design and implementation of educational games: Theoretical and practical perspectives (pp. 293-314). IGI Global. doi: https://doi.org/10.4018/978-1-61520-781-7.ch020

Sriwahyuni, N. A. (2016). Pengembangan media pembelajaran game edukasi pada mata pelajaran ekonomi kelas X IIS SMA Laboratorium Universitas Negeri Malang. Jurnal Pendidikan Ekonomi (Economic Education Journal), 9(2), 133-142. Retrieved from http://journal.um.ac.id/index.php/jpe/article/view/7160

Suartama, I. K. (2010). Pengembangan multimedia untuk meningkatkan kualitas pembelajaran pada mata kuliah media pembelajaran. Jurnal Pendidikan Dan Pengajaran. https://doi.org/http://dx.doi.org/10.23887/jppundiksha.v43i3.130

Subiyanto, S. (2017). Inovasi permainan kotak misteri pada pembelajaran PKN materi sistem pemerintahan. Jurnal Inovasi Pembelajaran Karakter, 2(2), 1-8. Retrieved from https://irpp.com/index.php/jipk/article/view/824

Sudjana, N. (2012). Dasar-dasar proses mengajar. Bandung: Sinar Baru Algensindo.

Sugiyono, S. (2010). Metode penelitian kuantitatif, kualitatif, dan R\&D. Alfabeta.

Ubaedillah, A., \& Rozak, A. (2013). Pendidikan kewarganegaraan (civic education): Demokrasi, hak asasi manusia, dan masyarakat ( $3^{\text {rd }}$ ed.). Jakarta: Kencana Prenada Media Group. 